\title{
A política externa da Federação Russa: recursos energéticos como vetor, Gazprom como instrumento
}

Franco Tomassoni*

\section{Resumo}

O contexto geopolítico contemporâneo vive uma fase de profunda mutação. Novos países questionam profundamente a configuração unipolar que se criou após a fim da assim chamada "Guerra Fria". A emersão de novas potencias econômicas e de estados que procuram um desenvolvimento autonomo é hoje um facto evidente. A fortalecer esta tendência está a criação de aliançais inter-estatais tanto regionais como a nível global (BRICS). Neste quadro a Federação Russa tem um papel central, e depois da década dos 90, que a viu ocupar um papel mundial de segundo ordem, volta a ser uma potencia reconhecida em nível planetário. Os instrumentos desta subida são: separação entre negócios privados e interesses estatais e fortalecimento do papel das empresas publicas; consolidação da própria presença na região; utilização dos próprios recursos energéticos (tirado das mãos dos privados) para financiar a própria economia e fortalecimento de aliançais com vários países e potencias econômicas nas varias regiões do mundo.

Palavras-chave: Gazprom; Putin; Política energética.

Membro da Associação Marx 21 - Itália. Mestrando em relações internacionais na FCSH - Universidade Nova de Lisboa - Lisboa, Portugal (maurelio@cfh.ufsc.br).

Geosul, Florianópolis, v. 28, n. 56, p 7-32, jul./dez. 2013 
TOMASSONI, Franco. A política externa da Federação Russa: recursos ...

The external politics of Russian Federation: energetic resources as vector, Gazprom as au instrument

\section{Abstract}

The geopolitical framework is in deep changing. The emersion of new countries and new economy put in crisis the unipolar framework originate since the end of the cold war. The rise of the new economics power who looking for an autonomous development today is undeniable. This tendency is strengthened by the inter-state alliances in regional such as in global level. In this framework the Russian Federation has an important role, and after the ' 90 s, where it was subordinate to the interest of the foreigners capital, today it has recover a role of international power. The principal features that characterize this shift are: a division between the private interests and the state ones, with a strong role of the public enterprise; a consolidation of his regional position; the employ of his natural and energetic resources (took away by the privates hands) as a financial instrument for the internal needs and, last but not least, a strong fortification of his international alliances. Key words: Gazprom; Putin; Energy policy.

\section{Introdução}

São vários os estudos que se ocupam da análise da política externa da Federação Russa. Este país, por vários fatores, tem um papel inopinável na política internacional. Aqueles que aqui são tomados em conta são: a sua posição geográfica, entre a Ásia e a Europa, que determina também a sua política regional; a composição orgânica do seu subsolo, que the confere grande abundância de recursos energéticos. São exatamente estas coordenadas, posição geográfica e riqueza em recursos energéticos, que determinam maioritariamente os vetores da sua política externa. A necessidade da consolidação regional é central para a tranquilidade essencial ao desenrolar das trocas comerciais, 
TOMASSONI, Franco. A política externa da Federação Russa: recursos ...

especialmente se se trata de recursos energéticos. A necessidade de exploração de novos jazigos e de construção de gasodutos exige um contexto regional que, na relação entre os estados da região, seja pacífico e de prosperidade. A posição geográfica da Federação Russa permite ao governo do país conduzir negócios energéticos tanto com a Europa Ocidental, como com a Ásia e os estados em crescimento econômico.

São estes, basicamente, os objetivos perseguidos pela Federação Russa na condução da sua política externa. Todavia, não foi sempre assim. Para perceber bem como muda a política externa russa nos últimos 20 anos e como este estado se posiciona no atual contexto mundial, é preciso adotar uma perspectiva capaz de ter em conta dados políticos, bem como processos históricos.

\section{A Federação Russa no contexto mundial}

O general de Gaulle nunca se referia à URSS, mas falava sempre de la Russie. Com isso sublinhava o fato de que, não obstante a mudança profunda de regime interno - marcada por uma revolução que, entre os seus efeitos, teve o de contribuir para a paz na Europa durante a Primeira Guerra Mundial, assim como na Segunda Guerra, em que desempenhou papel na derrota do nazifascismo (portanto que não encaminhava o país num rumo expansionista e de carácter colonialista) -, o país de Pedro $o$ Grande e de Stalin não deixava de se comportar como uma potência. Provavelmente, o general de Gaulle errava ao não ver uma solução de continuidade na história da Rússia, contudo, acertava num ponto preciso: la Russie, ao longo da história do século XX, teve uma importância indiscutível na política internacional. Este é um fato unanimemente reconhecido.

Com o fim da guerra fria e as mudanças na zona da exURSS, la Russie tornou-se na mais modesta Federação Russa, deixando a posição central que teve em quase todo o século XX. O período pós-URSS é marcado pelas liberalizações e privatizações dos seus principais setores estratégicos, transformando o país de 
TOMASSONI, Franco. A política externa da Federação Russa: recursos ...

potência em estado cuja política, indústria e economia são dominadas por grupos privados. Como se verá adiante, a liderança de Putin e de Medvedev muda esta situação.

Depois da década de 90, configura-se uma nova situação nas relações de poder internacional. Todavia, este cenário - que alguém saudou com excessivo entusiasmo, vendo no fim da URSS a afirmação de um só modelo de desenvolvimento e, simultaneamente, um mundo que pela primeira vez se mostrava com uma só superpotência a liderá-lo, sem nenhum concorrente (BRZEZINSKI, 1997) - nos primeiros anos do novo milénio muda de novo para uma direção multilateral. Este processo acelera-se com a crise econômica de 2007/2008 que enfraquece os países ocidentais em termos industriais, ergo financeiros. Não é por acaso que muitos analistas falam de 'crise atlântica', em lugar da expressão 'crise mundial'.

O quadro em que a Federação Russa vai desenvolver a sua política é, portanto, marcado pela emergência de novos países e economias que questionam o eixo estratégico daquele contexto unilateral. Multiplicam-se coligações de estados que se ocupam de todos os aspetos da política: econômico, institucional, militar e de segurança. Estes processos de integração são os quadros em que estas economias emergentes desenvolvem papéis de agentes internacionais, passando de meros atores a protagonistas.

A Federação Russa está envolvida na Organização para a Cooperação de Xangai (OCX), na Organização de Cooperação da Ásia Central (OCAC), na Comunidade dos Estados Independentes (CEI), na Organização do Tratado de Segurança Coletiva (OTSC), é membro do Conselho de Segurança da ONU, do G8 e do G20. Além disso, a Federação Russa tem um quadro de cooperação com países europeus e com a União Europeia (UE) que visa a consolidação de um espaço comum ao nível econômico e de segurança, entre outros. Acrescem ainda os acordos bilaterais comerciais/energéticos que tem com os países europeus e que objetivamente aumentam a sua influência dentro da UE. Mais ainda, a presença da Federação Russa nos BRICS permite-lhe ter 
TOMASSONI, Franco. A política externa da Federação Russa: recursos ...

uma projeção global da sua própria economia e orientar, num contexto multilateral, a sua presença em várias regiões do globo. Processo este que se aprofundou na sequência da última cúpula dos BRICS, em que se decidiu criar um banco para os países em vias de desenvolvimento, sendo um dos pilares principais deste mesmo banco o investimento no diversificado setor das infraestruturas. A relevância desta coligação de estados, e o papel da Federação Russa no seu seio, pode ver-se igualmente na cooperação com a China em razão da questão síria, importante para a Federação Russa devido à sua base militar em Tartus. O papel da Federação Russa e da China hoje é um obstáculo a uma intervenção militar. direta neste país.

A consolidação do papel global da Federação Russa tem como ponto de partida a sua consolidação regional. A área de influência na zona caucásica e da Ásia Central, região marcada pela presença de vários atores - que fazem voltar à memória o great game kiplinghiano -, é de interesse vital. Os processos internos de mudança destes estados referem-se aqui àqueles conhecidos como revoluções coloridas, financiados pela Soros Foundation, National Endowment for Democracy (NED) e International Republican Institute (IRI) principalmente, e tiveram oposição por parte da Federação Russa, que se opôs também fortemente à tentativa de alargamento a leste da OTAN.

$\mathrm{Na}$ capacidade de utilizar os seus recursos energéticos, de construir sólidos acordos multilaterais e bilaterais (energia e multilateralismo são, na perspectiva aqui defendida, os vetores principais da política externa deste país) e de se focar numa consolidação regional, isso tudo dentro de um desenvolvimento mundial que visa a multipolaridade, está contida uma mensagem clara: la Russie voltou.

\section{Putin, Medvedev, Moscovo, São Petersburgo: A transição para o sistema Putin}


TOMASSONI, Franco. A política externa da Federação Russa: recursos ...

O sistema político russo não se pode entender com a utilização das categorias cuja raiz reside na história e no desenvolvimento político da Europa Ocidental. Os dois elementos que definem o sistema político russo são "democracia soberana" e "verticalização do poder".

O conceito de democracia soberana elaborado pelo Kremlin tem três implicações principais: no centro do sistema político internacional está o estado, não outros atores como ONGs ou empresas multinacionais, supondo-se uma paridade entre os estados, apesar da sua ordem interior; produz uma distinção entre estados que são completamente soberanos e aqueles que não o são, deduzindo-se assim que os segundos não podem participar de forma abrangente nas dinâmicas de mudança internacional; é um modelo utilizado pela Federação Russa para ganhar a lealdade dos estados da Ásia Central, com os quais partilha projetos econômicos, institucionais e culturais (ISPI, 2011).

O conceito de "verticalização do poder" é marcado pela potente e profundamente centralizada máquina burocrática da Federação Russa que, todavia, não é demasiadamente diferente da de outros países. Isto significa que é o Estado o detentor dos eixos principais do país e governa a luta entre os oligarcas pela aquisição dos recursos energéticos e dos setores industriais, enquanto todo o poder político está nas mãos do governo, com um papel decisivo por parte do presidente (ISPI, 2011).

Estes conceitos são mais facilmente compreendidos fazendose um breve recuo no tempo, permitindo assim vislumbrar a matriz histórico-política que os gera.

Com o fim da URSS, a Federação Russa vive uma época de instabilidade econômica e política muito profunda: a tentativa de dois golpes (1993 e 1998), a primeira guerra da Chechénia (19941996) e um default em 1998. A dominar o país está o turbocapitalismo e as liberalizações que levam à subida ao poder de um pequeno grupo de oligarcas (ISPI, 2009). Mais ainda, aquela que foi uma grande potência torna-se terreno de conquista por vários bandos criminais. O Ministro do Interior calcula que 40\% 
TOMASSONI, Franco. A política externa da Federação Russa: recursos ...

das empresas privadas, $60 \%$ das empresas estatais e $50 \%$ dos bancos sejam controlados pelo crime organizado. É do conjunto formado por esta criminalidade organizada e as velhas estruturas de poder que sai o sistema oligárquico que lidera o país desde o fim do período gorbachoviano até ao putiniano, conhecido pela expressão família Ieltsiniana (RAHR \& PACHOMOV, 1998).

É exatamente neste contexto que se afirmam as categorias salientadas e também de onde emerge Putin. Quando, no verão do 1999, Ieltsin o nomeia primeiro-ministro, tudo parece seguir a continuidade da política de modalidade oligárquica. Ninguém poderia imaginar que um homem que cresceu entre a administração da velha Leningrado e sucessivamente chamado a Moscou pelo mesmo Ieltsin, antes como chefe dos serviços administrativos da presidência (uma espécie de governo-sombra, central na gestão do poder) e, posteriormente, como chefe da FSB (sucessora da KGB), poderia representar uma "serpente no seio da familia".

Todavia, em pouco tempo percebe-se muito bem a orientação que Vladimir Vladimirovich tem na gestão do poder na white house russa. Chegado ao Kremlin, Putin coloca as coisas de forma clara: a política é uma coisa, a economia e os negócios são outra. Os homens de negócios que interferem nas questões do Estado não têm um futuro áureo; aos outros é deixada liberdade de ação, sob o pacto de evitar qualquer intromissão na estratégia de subida, e de regresso, da Federação Russa à política internacional.

É assim que os oligarcas, na administração do Estado, são substituídos pelos homens que partilham a mesma visão de Putin, o qual escolhe aqueles que lhe foram próximos na sua experiência na administração de São Petersburgo, e os homens mais perto de si na sua carreira de agente da KGB e da FSB (os membros desse grupo são definidos como siloviki, termo com que se designa os exagentes que fizeram parte dos serviços informativos e secretos da época soviética). É esta também a ótica com que se deve ter em perspectiva a relação com Medvedev. Os resultados desta política, que alguém descreve com a expressão "desprivatização" do Estado, foram uma clara divisão entre o poder político e o 
TOMASSONI, Franco. A política externa da Federação Russa: recursos ...

econômico que desencadeou energias que influíram no desenvolvimento econômico dos primeiros anos da década de 2000 (TRETJAKOV, 2008).

O regresso dos eixos estratégicos do país às mãos do Estado é a etapa principal para uma renaissance da Federação Russa como potência global. Os recursos energéticos têm o papel principal nesta dinâmica: a transição putiniana afetou as principais empresas estatais, designadamente do setor da energia, e a principal companhia, a Gaznovaya Promyshlennost (Gazprom). Na década de 90, Gazprom teve que resistir ao processo de privatização, contudo, a maioria relativa ficou para o Estado $(38 \%$, percentagem com que ficou até 2004). Nos primeiros anos da década de 2000, o governo da Federação Russa fez várias operações e conseguiu ter uma presença de mais de $50 \%$ no capital. A partir de 2000 , foi mudada a administração. $\mathrm{O}$ velho presidente nomeado por Gorbachev na altura da criação da Gazprom foi substituído por Medvedev e logo o administrador fiduciário foi substituído por Miller, ex-colega de Putin na administração de São Petersburgo.

\section{De todo o poder aos sovietes a todo o poder à Gazprom}

A Federação Russa é o maior exportador de gás do mundo e o segundo em termos de petróleo. As suas reservas de gás são mais de $25 \%$ das mundiais, as de petróleo mais de 6,2\%. Mais de 50\% das suas exportações são constituídas por gás e petróleo. Mais de $70 \%$ da produção destes dois recursos energéticos é exportada (IEA, 2009). É neste aspeto que se baseia a força da economia putiniana e da Federação Russa como superpotência energética; isto representa também a sua dependência face aos países compradores.

A maior companhia russa, aquela que gere este potencial geopolítico, é justamente a Gazprom, que controla 95\% das reservas, $90 \%$ da produção, é detentora das condutas energéticas e gere completamente o upstream. Esta companhia nasceu em 1989 com a decisão de Gorbachev de juntar o Ministério do Petróleo e o 
TOMASSONI, Franco. A política externa da Federação Russa: recursos ...

do Gás. O presidente desta companhia pública na altura da sua criação era Chernomyrdin, ex-Ministro Soviético da Energia, primeiro-ministro da Federação Russa entre 1993 e 1998, que, para a sua construção, se inspirou no modelo da italiana ENI. O Presidente do Conselho de Administração nesta altura era Vyakhirev.

A exportação de gás para a UE corresponde a $63 \%$ das exportações de gás da Federação Russa (IEA, 2009). Isto significa uma importância muito forte da UE para a economia russa. Embora o mercado europeu seja vital para a Federação Russa - uma relação de dependência recíproca que é bom tomar em conta quando assistimos a uma análise da questão energética e da relação UEFederação Russa na mídia -, este se vira cada vez mais para leste (IEA, 2009).

Na sua agenda repleta de eventos, o Presidente da República Popular Chinesa Xi Jinping, entre 21 e 23 de Março deste ano alguns dias antes de se encontrar novamente com o presidente da Federação Russa na África do Sul para a cúpula dos BRICS -, efetuou uma visita à Rússia. No centro do encontro estava precisamente um acordo energético. De um lado temos quem dispõe de uma imensa quantidade de gás e de vários recursos energéticos, do outro uma economia em grande expansão que dispõe de capital para o desenvolvimento da estrutura produtiva: nada mais simples. Em 2012, a China aumentou as importações de gás russo em mais de $33 \%$ e a procura de gás por parte da China cresce todos os anos (ASIANEWS.IT, 2013). Para a Federação Russa, uma expansão a leste tem também o objetivo de diversificar os seus compradores e de competir com as exportações dos EUA, que estão a desenvolver a extração de gás não convencional, o que pode questionar a liderança russa no mercado energético. Como se pode comprovar, a empresa Gazprom encontra-se no núcleo dos negócios entre o estado russo e os seus parceiros.

Embora o eixo Kremlin-Gazprom não nasça com Putin Chernomyrdin e Vyakhirev foram aliados nas eleições de 1995 com o partido "Nossa Casa Rússia", renomeado na mídia como 
TOMASSONI, Franco. A política externa da Federação Russa: recursos ...

"Nossa Casa Gazprom" -, na sua presidência esta empresa pública torna-se um instrumento central na condução da política externa (GRAZIOLI, 2010). Pode-se afirmar com tranquilidade que os recursos energéticos são um dos vetores principais da política externa russa e a Gazprom o instrumento mais favorecido deste vetor.

Esta empresa é um verdadeiro Global Player. Não se ocupa exclusivamente dos processos do upstream: aquisição dos direitos de exploração, extração, produção, transformação, distribuição e comercialização. Com as centenas de empresas que controla e, com as suas filiais, esta companhia está presente no setor de mídia e no setor financeiro, tanto na Rússia como no resto do mundo.

Com a sua política de diversificação de compradores e de investimento em projetos a longo prazo, a Gazprom envolve relações estreitas tanto com os estados, como com companhias estatais, bem como com entidades privadas. Em 2005, a conduta Bluestream entre Rússia e Turquia está em completo funcionamento. Em 2006, a companhia russa assina com a italiana ENI o memorando para o Southstream e começa a preparação para a plataforma offshore no Mar de Barents, como base das reservas de gás que, com o Northstream, serão enviadas para a Alemanha. Parceiros deste projeto são a francesa Total e a norueguesa StatoilHydro (GRAZIOLI, 2010). A primeira linha do gasoduto Northstream foi inaugurada em 2011, a segunda em 2012. A Gazprom detém 51\% da companhia que gere este pipeline (North Stream AG) e tem parceiros alemães, franceses e holandeses. Mais, a Gazprom aumenta a produção de GNL, gás líquido natural e em 2005 envia a sua primeira carga para os EUA, em 2009 assina com a empresa Shell um contrato de fornecimento até 2028. Além disso, existem cooperações com os países ex-soviéticos e da grande região asiática. Finalmente, refira-se os acordos com as companhias latino-americanas, onde a necessidade de uma cooperação sobre os recursos se junta a exigências geopolíticas mais amplas. 
TOMASSONI, Franco. A política externa da Federação Russa: recursos ...

Como se pode ver, a Gazprom está envolvida nas principais áreas econômicas do mundo com acordos comerciais e de cooperação econômica a longo prazo e projetos de gasodutos e plataformas offshore com empresas estatais e privadas. Esta presença global, que avança dentro de um quadro complexo da estratégia de política externa da Federação Russa, rende-lhe um importante instrumento geopolítico. Olhando as medidas adotadas por Putin, e sucessivamente por Medvedev, sobre a questão da energia, a impressão é a de que os recursos energéticos são efetivamente uma potente arma política que visa a consolidação da estratégia internacional russa. De fato, um dos efeitos da transição putiniana é a limitação das companhias estrangeiras e dos direitos de exploração das companhias privadas, uma vez mais se afirmando o conceito de "democracia soberana" já salientado. Mais, a fortalecer esta estratégia está a implementação de novos projetos de gasodutos que visam uma diversificação dos canais de distribuição, de modo a evitar aqueles que possam criar problemas ao comércio de gás.

A relevância da energia no conceito nacional de defesa vê-se bem na relação entre a Federação Russa e os países limítrofes. As disputas com os países de trânsito e que são importadores do gás russo têm que ser olhadas na perspectiva da consolidação regional. A partir de 2004 houve várias disputas, designadamente nos países da Europa Oriental, basicamente desencadeadas por questões referentes aos preços dos recursos energéticos, que tiveram como resultado a suspensão do fornecimento de gás (DIMITRAKOPULOU \& LIAROPOULOS, 2010).

Todavia, a realidade está bem longe de como várias mídias europeias a mostram. A essência destas disputas é resumível a duas frases, uma referida por Alexander Medvedev, presidente da Gazprom Export, a outra por Putin. "Na Europa existem duas visões: as empresas com as quais temos ótimas relações sabem que somos parceiros fiáveis. Os políticos mostram-nos como os inimigos dos filmes de James Bond, prontos a deixar o continente sem gás. Eu pergunto: porque temos de gastar 25 bilhões de 
TOMASSONI, Franco. A política externa da Federação Russa: recursos ...

dólares para a construção de gasodutos como o North e o South Stream, só para fechar as torneiras e procurar danos nas duas economias?" (MEDVEDEV, 2009). E Putin, com toda a lucidez da realpolitik responde ao entrevistador da Time, que em 2007 o nomeou Person of the Year, sobre a questão das disputas com os países ex-soviéticos: "There are world prices, international prices for gas. And we sell gas to everyone at world market prices. Why should we sell to anyone below the world market prices? Do Americans sell to anyone below the market price? Could you come to a store in the United States and ask, well, I'm from Canada, we Canadians are close neighbours; give me that Chrysler at half price. What would you hear from the salesman? Go away!" (TIME, 2007).

Isto demonstra, por um lado como a política energética russa está inserida dentro das dinâmicas do mercado e como, em conformidade com esta dinâmica, o governo visa o máximo lucro. Por outro lado, todavia, mostra como a política regional, se precisa utilizar o porrete, não o pode fazer sem a cenoura. A Federação Russa é tão dependente das suas exportações, e, por isto, das infraestruturas e do quadro jurídico que as regulamentam nos países da Europa Centro-oriental, que tem sempre que fazer uma síntese, reagindo de forma brusca só quando vê a tentativa, às vezes concertada dentro de uma contratação global, de um redimensionamento.

Isto mostra, sim, a exigência para a Federação Russa de uma política de cooperação regional, mas também mostra a existência de uma tentativa de potências de outras regiões, de intervir diretamente nos assuntos internos dos países da região do Cáucaso e da Europa Oriental com uma função de containment na sua versão que podemos definir 2.0, em relação à Rússia e aos seus parceiros estratégicos.

Pode-se, portanto afirmar que a Gazprom é um instrumento central na gestão da política externa russa, cuja utilização não mudou nos últimos 15 anos, apesar de serem Putin ou Medvedev a liderar o país. Isto porque os recursos energéticos são um dos 
TOMASSONI, Franco. A política externa da Federação Russa: recursos ...

vetores principais da política externa russa e a Gazprom é apenas quem gere este potencial. É importante reassumir os principais fatos até aqui mencionados: com Putin inicia-se um processo de consolidação do papel do estado na política energética baseada num controle forte deste setor e na simultânea restrição do papel das companhias privadas e estrangeiras; Putin também adjudica projetos de gasodutos para contornar os países de trânsito. Medvedev prosseguiu nesta direção introduzindo de forma abrangente a questão energética na estratégia nacional de segurança $^{1}$ e continuando e desenvolvendo os projetos de gasodutos adjudicados por Putin, para contornar países de trânsito.

\section{Gazprom e a Rússia na crise de $\mathbf{2 0 0 8}$}

É correta a expressão "crise atlântica" para definir a crise económica de 2008? Se esquecermos do sentido geográfico do termo "atlântica" e focarmos esta definição no espaço entre a Europa Ocidental e os EUA, esta expressão é correta. Como já foi sublinhada, esta crise do setor financeiro, mas radicada num excedente produtivo, enfraqueceu as economias norte-americana $\mathrm{e}$ europeia mais que as outras. Este fato contribuiu fortemente para a aceleração da emergência de outras economias. A Federação Russa desfrutou deste acontecimento pelo fato de estar ligada a uma relação não exclusivamente econômica, mas também de ordem geopolítica, com as economias emergentes, e até militar e de segurança, como se vê na sua relação com a China.

Todavia, a economia não funciona em compartimentos estanques e as profundas conexões e as macro-dinâmicas mundiais, não obstante de forma e intensidade diferentes, afetam todos os atores da cena global. A maxi-empresa pública russa das energias

${ }^{1}$ Em cada documento de segurança nacional da Federação Russa, a energia tem o seu espaço, embora no documento de 2009 a questão da energia tome um papel muito importante em toda a elaboração do documento, que assume o papel de pilar da segurança nacional. 
TOMASSONI, Franco. A política externa da Federação Russa: recursos ...

não é uma exceção. Em 2007 a sua capitalização de mercado era de mais de $\$ 330$ bilhões, mesmo em maio de 2008 esta capitalização era de mais de $\$ 360$ bilhões, mas, no fim desse ano, a Gazprom acabou com uma capitalização de mercado de pouco mais de $\$ 86$ bilhões, com uma perda de mais de $74 \%$ no índice MICEX da bolsa moscovita (GAZPROM, 2012). Em maio de 2008 a Gazprom foi a terceira em termos de valor de capitalização, depois da General Electric e da China Mobile, mas nesse ano as suas ações diminuíram mais de $13 \%$ e chegaram a um valor de pouco mais de $\$ 100$ cada. Contudo, o número 1 da companhia, Aleksei Miller, declara em 2008 que em 7-10 anos a Gazprom será a primeira companhia mundial por capitalização de mercado, passando para o valor de \$1 bilhão (IL SOLE 24 ORE, 2008).

É preciso sublinhar um aspecto. Entre 2000 e o primeiro semestre de 2008 a economia russa tem um nível de crescimento elevado do PIB, com taxas entre 5,1\% e 7,2\%. Os principais aspectos que contribuem para este avanço são o crescimento dos preços do petróleo, juntamente com reformas econômicas feitas pelo governo, designadamente a reforma do sistema fiscal para as empresas. Em 2007, a Goldman Sachs publica como acontece desde 1997, a Groeth Enviroment Score, classificação de rating das economias emergentes, e a Federação Russa obtém a melhor posição entre as economias da área BRICS pela positividade dos seus indicadores econômicos (BANCA INTESA, 2008).

A crise econômica que se instala, entretanto, mostra as fraquezas da economia russa e os seus limites. O mais relevante é a fraca diversificação da sua economia, que a leva à crise com uma diminuição da procura mundial de recursos energéticos. Todavia, as suas perspectivas são positivas: o FMI melhora as previsões de crescimento para 2011. Mais, nas previsões da Pricewaterhouse Coopers, em 20 anos a Federação Russa terá preenchido todos os requisitos para ser a primeira economia europeia (BANCA INTESA, 2010). 
TOMASSONI, Franco. A política externa da Federação Russa: recursos ...

\section{Rússia-UE e as pipelines. Southstream vs. Nabucco}

1. Como já foi salientado várias vezes, um dos objetivos principais da Federação Russa é a diversificação dos compradores, bem como a diversificação dos canais de distribuição. Efetivamente, se olharmos para as disputas dos últimos anos entre a Rússia e os países em que os gasodutos passam, este objetivo tem uma grande importância estratégica.

O projeto Southstream vai neste sentido. É promovido e financiado pelas empresas Gazprom, ENI, EDF e Wintershall e, atravessando o Mar Negro, propõe-se a transportar o gás diretamente aos consumidores do sul e do centro da Europa. O investimento necessário é de mais de 25 bilhões de euros e pode chegar inclusive a transportar 63 bilhões $\mathrm{m}^{3}$ ao ano. Pelo fato de contornar países como a Ucrânia, que pode ser fonte de problemas, este gasoduto representa uma vantagem para a segurança energética tanto da Rússia, porque visa a uma estabilização da procura, como da UE, porque a coloca em segurança no que diz respeito aos fatores desestabilizadores representados pelos países de trânsito.

2. Antes de detalhar o debate entre southstream e o seu competidor mais próximo, o Nabucco, vamos ver os dados principais para ter uma ideia geral. Em 2011, o mix energético da UE foi o seguinte: a) petróleo 646 mtep (38\%); b) gás 403 mtep (24\%); c) carvão 286 mtep (17\%); d) nuclear 205 mtep (12\%); e) renováveis 81 mtep (5\%); f) hidroelétrico 70 mtep (4\%). Os fornecedores foram: a) UE (34\%); b) Federação Russa (24\%); c) Noruega (19\%); d) Argélia (9\%); e) Qatar (7\%); f) outros (7\%). Mais, num intervalo de tempo entre 1980 e 2007 e o primeiro semestre de 2008 temos três indicadores de tendência que descrevem as dinâmicas energéticas europeias: aumento dos consumos energéticos em termos absolutos; esgotamento das fontes endógenas de gás; aumento do peso do gás no mix energético (FLOROS, 2012). 
TOMASSONI, Franco. A política externa da Federação Russa: recursos ...

A crise econômica tem um efeito duplo, ou seja, o de diminuir a procura de gás no imediato, e um efeito de desindustrialização - segundo a lei macro-econômica muito bem ilustrada por Marx, pela qual a uma diminuição da taxa de proveito corresponde um aumento da produção da mais-valia absoluta (ou seja, ganha com uma exploração maior do tempo de trabalho capital variável) e uma diminuição da mais-valia relativa (efeito de uma constante redução do capital fixo: capital representado pelas máquinas industriais) - que tem como resultado uma menor procura de energia. Todavia, as perspetivas, também as piores, concordam no fato de que o consumo de gás não sofrerá uma mudança estrutural, não obstante não se prever que se desenvolverá tão rapidamente como alguns estudos tinham prognosticado ${ }^{2}$. Isto confirma a validade destes três indicadores tendenciais também para o futuro.

3. No quadro delineado temos principalmente dois fatores que mostram a utilidade da construção do Southstream: a diminuição da produção interna de gás da UE, e o aumento, ou pelo menos uma estabilização, da procura. De qualquer forma, precisa-se de um aumento das importações. Todavia, esta obra não é bem aceita pelos EUA, que várias vezes se exprimiram contrariamente e que atentam à construção do Nabucco (todavia não há empresas estadunidenses que financiem este projeto), um gasoduto que visa o transporte de gás do Azerbaijão até a Áustria. As razões dos EUA são bem compreensíveis, ou seja, é verdade que o aumento da dependência do gás russo pode tornar-se numa arma de pressão da Federação Russa sobre os países europeus. Contudo, a relação que as três maiores economias da zona euro, Alemanha, França e Itália, têm com a Federação Russa não é de subordinação, mas de interdependência recíproca. É também verdade que, não obstante os EUA se vangloriem por serem o país mais liberal do mundo, a utilização da energia como arma

${ }^{2}$ É preciso confrontar os estudos da IEA, da Gazprom e do ISPI, que se podem encontrar nos respetivos sítios, nos anos entre o 2007 e 2012. 
TOMASSONI, Franco. A política externa da Federação Russa: recursos ...

geopolítica não é uma prioridade ou particularidade da Federação Russa. Em 2005, com explícito veto do governo Bush, a companhia chinesa CNOOC não conseguiu adquirir a californiana UNOCAL.

Um elemento que em no futuro poderá ser um ponto de força para o Nabuco é o fato de que o ritmo mais rápido de crescimento de procura de energia na Ásia pode fortalecer uma dinâmica de viragem a leste por parte da Federação Russa. A diversificação dos vendedores é, portanto, um elemento que fortalece a segurança energética da UE. Todavia, este projeto, que toma o nome da obra lírica de Giuseppe Verdi, o qual pretende transportar o gás desde a base Shah Deniz II no Azerbaijão (liderada pela British Petroleum), não parece ser financeiramente sustentável, dado que a quantidade de gás fornecida por esta base é insuficiente, deficit ao qual se acrescenta uma carência de capital imediato (FLOROS, 2012).

Para suprir este problema existe a possibilidade de os países envolvidos neste projeto, juntamente com outros da UE, investirem no gasoduto transcaspiano (Trans Caspian Pipeline - TCP), que garantiria aos países da UE o gás das repúblicas caucásicas. Mas isto também demonstra uma limitação nada pequena. A questão jurídica do Mar Cáspio não está definida e, para a construção de um gasoduto, é necessária a autorização de todos os países que são banhados por este mar, entre os quais está a Federação Russa. O mercado é procura e oferta e os gasodutos são apenas o que fica no meio. Se não ficar clara a relação entre oferta e procura, podem-se construir milhões de gasodutos, sem que, porém, tenham qualquer função. Ademais, assaz problemático para o TCP, único gasoduto que torna financeiramente sustentável o projeto Nabucco, é o papel do Turquemenistão, que desde logo assinou para fazer transitar o próprio gás para a Rússia.

\section{As implicações geopolíticas do gás não-convencional}


TOMASSONI, Franco. A política externa da Federação Russa: recursos ...

A entrada em cena no mercado mundial dos recursos energéticos do gás não-convencional acontece devido ao desenvolvimento da técnica extrativa, e, hoje em dia, é uma realidade. A sua produção nos EUA é desenvolvida rapidamente na primeira década de 2000 e em 2010 representa $20 \%$ da sua produção de gás (KEFFERPUTZ, 2010). Ainda mais relevante é o fato de em 2010 a quantidade de gás produzido nos EUA ser cerca de $100 \%$ da produção de gás natural exportado da Federação Russa (NICOLAZZI, 2010). Alguns estudiosos falam de uma "nova época de abundância" pelo fato de que o desenvolvimento de novas tecnologias permite atingir depósitos até agora não explorados. Nesta primeira década de 2000 os EUA projetavam aumentar as importações, mas logo perceberam que estavam sentados sobre uma reserva poderosa de recursos energéticos (MAFODDA, 2011).

Contudo, as perspectivas não são claras: por um lado temos quem defende que os recursos definidos como não-convencionais vão reconfigurar estruturalmente a geografia da energia mundial, marcando uma mudança do atual contexto macroeconómico da energia. Do outro lado, temos quem se opõe frontalmente a esta análise. Michel A. Levi, do think tank Council on Foreign Relations, considera que estes novos recursos provavelmente resultarão numa diminuição dos preços, ainda que não mudarão a geografia energética e, no máximo, diminuirão os riscos, mas não evitarão os choques na oferta de recursos no sistema internacional (LEVI, 2011).

Para o continente europeu, esta questão apresenta algumas complicações. Na perspectiva da IEA contida no World Energy Outlook 2009, o nosso continente parece ser rico nestes recursos: "unconventional resources in OECD Europe are large enough to displace 40 years of imports of gas at the current level, assuming recovery rates in line with those in North America" (IEA, 2009). Todavia, existem algumas complicações. A primeira é representada pelos direitos sobre o subsolo. Estes, ao contrário do que acontece nos EUA, onde o subsolo é privado, o que gera um grande lucro pelos privados devido às suas concessões, tem na Europa uma 
TOMASSONI, Franco. A política externa da Federação Russa: recursos ...

propriedade estatal. Além disso, o velho continente é mais densamente povoado, fato que pode desencadear movimentos de protesto de tipo NIMBY (Not in My Back Yard), contra um processo extrativo com grande impacto ambiental. Aliás, é necessária uma mão-de-obra especializada, portanto é preciso um processo de aquisição de know-how. Last but not the least, em comparação com os EUA, a Europa é carente de infraestruturas adequadas (KUHN\&UMBACH, 2011. KEFFERPUTZ, 2010).

O desenvolvimento das tecnologias da extração deste recurso não convencional tem também implicações no mercado asiático. $\mathrm{O}$ que é preciso é perceber a dinâmica e o peso real destas implicações, ou seja, se este recurso é capaz de impactar realmente as relações consolidadas da Rússia com os países asiáticos e principalmente com a China. No número de março-abril da revista Foreign Affairs de 2013, Kevin Rudd conclui o seu artigo de título "Beyond the Pivot - A New Road Map for U.S. - Chinese Relations" afirmando que chegou o momento de construir uma cooperação entre as duas potências sobre alguns temas importantes nos quais é possível encontrar uma convergência (RUDD, 2013). Não é possível saber quanto desta visão é partilhada pela administração estadunidense e quanto dela se baseia num espírito de cooperação. De qualquer maneira, adaptado-a ao tema do gás não-convencional, isto significa que: "Naturally, countries like China, which is estimated to hold more shale gas then the US and Canada combined, are hungry to learn the secret to their success. This may be just the carrot of diplomacy the US seeks to hold greater interaction with Beijing" (BRENNAN, 2013). Fica claro o fato de que a China está à procura de uma política energética autónoma e diversificada, tanto de recursos, para ter uma matriz energética mais flexível, como de vendedores. De toda a forma, na opinião aqui defendida, isso está longe da representar uma mudança na colocação estratégica do grande estado asiático e na escolha dos seus parceiros.

Fica portando claro - concluindo esta parte focada nos recursos não convencionais, nomeadamente o shale gas, e dos seus 
TOMASSONI, Franco. A política externa da Federação Russa: recursos ...

impactos no mercado energético - que a possibilidade de utilizar novos recursos energéticos questiona os países produtores e exportadores. A nível teórico, um forte crescimento da extração de recursos não convencionais representa uma ameaça para a Federação Russa, especialmente se se partilha a opinião de que estes recursos podem redefinir a geografia energética. Todavia, a Rússia não deixa de ser central no mercado energético europeu, e a relação deste país com a China tem um valor que vai para além de uma troca comercial.

\section{Conclusões}

1. Os vetores da política externa da Federação Russa são principalmente dois: o multilateralismo e os recursos energéticos utilizados como instrumento de posição externa. Estes são dois fatores que constituem uma ligação indivisível. Os recursos energéticos são um instrumento fundamental para financiar o PIB deste país. Se forem subtraídos ao produto russo, o crescimento econômico torna-se recessão. Esta posição privilegiada da Federação Russa no setor energético precisa, contudo, de um contexto regional e global seguro. Qualquer tentativa de intromissão por parte de outra potência na área de influência da Federação Russa é vista, com razão, como tentativa de questionar a sua posição. É por isto que a Federação Russa conduz uma política que visa a consolidação de um contexto multilateral que a vê cooperar com países da UE, países asiáticos, dentro de organizações regionais e em cooperação com outros países acerca do tema da segurança. No contexto internacional, a Federação Russa tentou evitar a guerra contra a Líbia e agora é um dos principais obstáculos a uma guerra contra a Síria. Isto pelo fato de a Líbia ter sido um aliado da Federação Russa e a Síria ainda o ser (atendendo aos desenvolvimentos futuros), e que existe uma forte preocupação na administração putiniana de que vastas regiões do globo estejam numa condição de instabilidade estrutural (como já em parte o é) e sob uma única influência. 
TOMASSONI, Franco. A política externa da Federação Russa: recursos ...

2. É seguramente verdade que a Federação Russa utiliza os seus recursos como arma política, mas isto pelo simples fato de que, para gerir os próprios recursos energéticos, existem duas modalidades: deixar que sejam geridos pelos grupos privados, muitas vezes sem que os estados detentores desfrutem dos proveitos, ou enquadrar os recursos numa estratégia geopolítica em que o estado tem um papel central. Para, além disso, o fato de Schröder se ter tornado membro do conselho de administração do Southstream causou grande escândalo pelo motivo de evidenciar uma ligação internacional entre economia e política, ligação essa que existe em qualquer região do mundo. Isto é relevante porque significa que a Rússia aprofunda a sua própria capacidade de influenciar a política da União Européia. Pelo contrário, não suscitou nenhum frisson o fato de Lord Robertson, secretário-geral da OTAN, se ter tornado membro da British Petroleum (PB) (GRAZIOLI, 2010).

3. O mercado prioritário para a Rússia é hoje em dia a União Européia, não obstante o mercado asiático desenvolver-se rapidamente. Todavia, a relação não é de sentido único. A Federação Russa também precisa diversificar os compradores, porque a sua relação com a Europa é de dependência. Mas não só por isso. A Rússia precisa diversificar a sua economia porque esta não pode depender exclusivamente dos recursos energéticos. Estes são hoje e já há algum tempo utilizados como instrumento da política internacional, bem como principal instrumento para um regresso da Rússia ao centro da economia global, para o qual, porém, não é ainda suficiente. Não bastam as reservas e os recursos para se ser rico. Se assim fosse, a Nigéria, assim como o Congo, seriam países florescentes e desenvolvidos.

4. Para uma maior compreensão sugerimos dois conceitos formulados por Giovanni Arrighi que, partindo de uma profunda análise histórica/econômica/financeira, se referem ao contexto atual como um período de transição marcado por uma crise hegemônica. O primeiro: a expansão financeira global não é um novo estágio do desenvolvimento do sistema capitalista, nem o 
TOMASSONI, Franco. A política externa da Federação Russa: recursos ...

estágio anterior de um domínio absoluto dos mercados em que o estado-nação deixa de existir, mas sim o traço distintivo de uma crise hegemônica, que pode acabar mais ou menos catastroficamente, dependendo do comportamento da potência que perde a sua hegemonia. O segundo: o caráter mais importante e peculiar da atual crise hegemônica é uma distribuição dos recursos financeiros e militares que, em transições passadas, sugere o autor, estavam concentrados no mesmo estado e que hoje têm uma forma diferente, estando localizados em áreas diferentes do globo (ARRIGHI, 2003). Estes dois aspetos representam o prisma através do qual se pode observar a situação atual. O contexto mundial visa uma peculiar forma de multipolaridade. A Federação Russa faz o seu jogo dentro deste quadro, tentando o melhor resultado possível. Os instrumentos dos recursos energéticos funcionam dentro destas dinâmicas globais, nem sempre previsíveis. Todavia, a Federação Russa escolheu um campo estratégico claro: a presença nos BRICS.

Face a esta situação, é oportuno concluir com uma expressão que parece particularmente adaptada a este contexto: o velho morre e o novo não pode nascer. Nesse interregno verificam-se os fenômenos mais variados. Esta expressão de Gramsci, embora formulada por outro acontecimento histórico, mostra exatamente o movimento dialético nos processos de transição, tal qual no processo contemporâneo que estamos a viver.

\section{Referências bibliográficas}

Arrighi, G., 2003. Caos e governo del mondo, Mondadori, Milano.

Asianews, 2013. Con le "anime aperte”, Mosca e Pechino si scambiano petrolio e gas. [press release] 23 Março 2013. Available at: http://www.asianews.it/notizie-it/Con-le-animeaperte,-Mosca-e-Pechino-si-scambiano-petrolio-e-gas-7477.html [accessed 9 Maio 2013]. 
TOMASSONI, Franco. A política externa da Federação Russa: recursos ...

Banca Intesa, notiziario intesa CSI, 7 Janeiro 2008.

Banca Intesa, notiziario intesa CSI, 8 Fevereiro 2008.

Brennan, E., 2013. The Key in the US' Asia Pivot? [online] Available at: http:/www.isdp.eu/images/stories/isdp-mainpdf/2013-brennan-shale-gas-asia-pivot.pdf [accesed: 27/5/2012].

Brzezinsky, Z., 1997. The Grand Chessboard: American Primacy and Its Geo-strategic Imperatives. Basic Books

Floros, D., 2012. South stream, il tubo della discordi, Limes, nr. 6/2012, pp.91-100.

Gazprom, 2011. Gazprom in figures 2007-2011 factbook. [pdf] Avaleable: http:/www.gazprom.com/f/posts/29/761233/gazpromreference-figures-2007-2011-eng.pdf [accessed, 9 Maio 2013].

Grazioli, S., 2010. Gazprom. Il nuovo impero. Roma, Lantana.

IEA, 2009. World Energy Outlook 2009.[online] Available at: http://www.worldenergyoutlook.org/media/weowebsite/2009/WEO 2009.pdf

IEA, 2011. World Energy Outlook 2011.[online] Available at: http://www.eia.gov/forecasts/ieo/pdf/0484\%282011\%29.pdf.

IEA, 2012. World Energy Outlook 2012.[online] Available at: http://www.eia.gov/forecasts/aeo/pdf/0383\%282012\%29.pdf.

Il sole 24 ore, Russia, crolla la capitalizzazione di Gazprom, 16 Outubro 2008. Available at: http://www.ilsole24ore.com/art/SoleOnLine4/Finanza\%20e\%20Me rcati/2008/10/gazprom-capitalizzazione.shtml?uuid=abd04864- 
TOMASSONI, Franco. A política externa da Federação Russa: recursos ...

9b93-11dd-adcf-7695700521e1\&DocRulesView=Libero [acessed: $27 / 5 / 2013]$.

Istituto per gli studi di politica internazionale (ISPI), 2009. La Russia di fronte alla crisi. Roma: ISPI.

Istituto per gli studi di politica internazionale (ISPI), 2011. I BRICs e noi. Roma: ISPI.

Kefferputz, R., 2010. Shale gas: la soluzione ai bisogni energetici europei? [online] Avaliable at: http://temi.repubblica.it/limes/shalegas-la-soluzione-ai-bisogni-energetici-europei/14546 [accesed: 27/5/2012].

Kuhn, M., \& Umbach, F., 2011. The geoeconomic and Geopolitical Implications of Unconcentional Gas in Europe. [online] Available

at: http://www.ensec.org/index.php?option=com_content\&view=articl e\&id=320:the-geoeconomic-and-geopolitical-implications-ofunconventional-gas-in-europe $\&$ catid=118: content $\&$ Itemid $=376$ [accesed: 27/5/2012].

Mafodda, G., 2011. Gli USA e l'abbondanza di idrocarburi "non convenzionali". [online] Avaliable at: http:/temi.repubblica.it/limes/gli-usa-e-labbondanza-diidrocarburi-non-convenzionali/30483 [accesed: 27/5/2012].

Medvedev, A., 2009. Il gas russo dipende dal'europa, facciamo accordi. La Repubblica, 24/05/2009. p.29.

Nicolazzi, M., 2010. Geopolitica delgi idrocarburi: istruzioni per l'uso. [online] Avaliable at: http://temi.repubblica.it/limes/geopolitica-degli-idrocarburiistruzioni-per-1\%E2\%80\%99uso/13403 [accesed: 27/5/2012]. 
TOMASSONI, Franco. A política externa da Federação Russa: recursos ...

Rahr, A \& Pachomov, P., 1998. Die Geschcte der russischen Kriminalitat. Berlin, DGAP.

Rudd, K., 2013. A New Road Map for U.S. - Chinese relations, Foreign Affairs, nr March/April 2013, pp. 9-15.

Time, 2007. Putin Q\&A. Time [online] Availeable at: $<$ http:/www.time.com/time/specials/2007/personoftheyear/article/0, 28804,1690753_1690757_1695787-7,00.html $>$ [accessed, 9 Maio 2013].

Tretjakov, V., 2008. Progetto Russia. Che cosa vogliono Putin e Medvedev, Limes, nr. 3/2008, pp.25-39

Recebido em setembro de 2013

Aceito em dezembro de 2013 